See discussions, stats, and author profiles for this publication at: https://www.researchgate.net/publication/273641200

\title{
Optimal design and plantwide control of novel processes for di-n-pentyl ether production
}

Article in Journal of Chemical Technology \& Biotechnology · March 2015

DOI: $10.1002 /$ jctb.4683

CITATIONS

11

6 authors, including:

Costin Sorin Bildea

Polytechnic University of Bucharest

182 PUBLICATIONS 1,384 CITATIONS

SEE PROFILE

(9.) Eduardo Sánchez Ramírez

Universidad de Guanajuato

34 PUBLICATIONS 110 CITATIONS

SEE PROFILE

Some of the authors of this publication are also working on these related projects:

Triethyl citrate production via reactive distillation View project

Project

PRISM - Towards knowledge based processing systems View project
Romuald Győrgy

Aristotle University of Thessaloniki

4 PUBLICATIONS 16 CITATIONS

SEE PROFILE

Juan José Quiroz-Ramírez

CIATEC

28 PUBLICATIONS 105 CITATIONS

SEE PROFILE 


\title{
Optimal design and plantwide control of novel processes for di-n-pentyl ether production
}

\author{
Costin Sorin Bildea, ${ }^{1}$ Romuald Győrgy, ${ }^{1}$ Eduardo Sánchez-Ramírez, ${ }^{2}$ \\ Juan José Quiroz-Ramírez, ${ }^{2}$ Juan Gabriel Segovia Hernandez, ${ }^{2}$ Anton A. Kiss ${ }^{3,4}$ \\ ${ }^{1}$ University "Politehnica” of Bucharest, Polizu 1-7, 011061 Bucharest, Romania. \\ ${ }^{2}$ Universidad de Guanajuato, Campus Guanajuato, División de Ciencias Naturales y \\ Exactas, Dept. de Ingeniería Química, Noria Alta s/n, 36050, Guanajuato, Gto., México. \\ ${ }^{3}$ AkzoNobel - Supply Chain, Research \& Development, Process Technology SRG, \\ Zutphenseweg 10, 7418 AJ Deventer, The Netherlands.E-mail:Tony.Kiss@akzonobel.com \\ ${ }^{4}$ Sustainable Process Technology Group, Faculty of Science and Technology, University of \\ Twente, PO Box 217, 7500 AE, Enschede, The Netherlands
}

\section{Abstract}

BACKGROUND: Di-n-pentyl ether (DNPE) is a good candidate for diesel fuel formulations due to its blending cetane number, good cold flow properties and effectiveness in reducing diesel exhaust emissions, particulates and smokes. However, novel processes are required in order to drive the production costs down and to increase the efficiency at industrial scale.

RESULTS: The dehydration of 1-pentanol to yield DNPE is catalyzed by thermally stable resins, such as Amberlyst 70 which has high activity and selectivity at temperatures up to 190 ${ }^{\circ} \mathrm{C}$. Two process options are proposed for a plant capacity of $26.5 \mathrm{ktpy}$ : a reaction-separationrecycle (R-S-R) system based on an adiabatic tubular reactor and a catalytic distillation process. Both processes were optimized in terms of total annual costs (481 and $523 \mathrm{k} \$$ /year), leading to specific energy requirements of 225 and $256 \mathrm{kWh} /$ ton DNPE, respectively. The controllability was assessed by dynamic simulation performed in Aspen Dynamics.

CONCLUSION: Compared with the membrane reactor reported earlier, the new DNPE process alternatives (i.e. conventional reaction-separation-recycle system and catalytic distillation) are better process candidates, requiring simpler units leading to much smaller investment costs, while also having good controllability.

Keywords: reaction-separation-recycle system, reactive distillation, design and control

\footnotetext{
*Corresponding authors'e-mail addresses: tonykiss@gmail.com, s_bildea@upb.ro
} 


\section{Nomenclature}

$2 a$

$4 \quad C$

$5 \quad D$

$6 \quad F$

$7 \quad F_{i}$

$8 \quad k$

$9 \quad K_{\text {eq }}$

$10 \quad L$

$11 \quad m$

$12 N_{T}$

$13 P$

$14 Q$

$15 t$

$16 \quad T$

$17 x$

$18 \omega$

19 Subscripts

20 cat

$21 \quad \mathrm{D}$

22 eq

$23 \max$

$24 \quad \mathrm{P}$

$25 \mathrm{R}$

26 W

Activity, -

Area, $\mathrm{m}^{2}$

Cost, US \$

Distillate flow rate, $\mathrm{kmol} / \mathrm{h}$

Feed flow rate, $\mathrm{kmol} / \mathrm{h}$

Correction factor (i=d,p,m / e.g. design, pressure, material), -

Reaction constant, $\mathrm{kmol} / \mathrm{kg}_{\text {cat }} \cdot \mathrm{s}$

Equilibrium constant, -

Length, $\mathrm{m}$

Mass, $\mathrm{kg}$

Number of trays, -

Pressure, bar

Heat duty, $\mathrm{kW}$

Time, min

Temperature, $\mathrm{K}$

Liquid mol fraction, -

Volume fraction, -

27 Abbreviations

28 CAPEX Capital expenditures

29 COM Component object model

30 DIPE Di-isopropyl ether

31 DNPE Di-n-pentyl ether

32 ETBE Ethyl tert-butyl ether

33 FEHE Feed-effluent heat exchanger

34 HP High pressure

35 LP Low pressure

36 MP Medium pressure

$37 \quad$ M\&S Marshall and Swift index

38 MTBE Methyl tert-butyl ether

39 OPEX Operating expenditures

40 PID Proportional integral derivative

41 RD Reactive distillation

42 RDC Reactive distillation column

43 R-S-R Reactor-separation-recycle

44 SQP Sequential quadratic programming

45 TAC Total annual cost

46 TAME Tert-amyl ether

47 TAEE Tert-amyl ethyl ether

48 THEME Tert-hexyl methyl ether 


\section{Introduction}

Along with the design of the diesel engines, the fuel quality is also a key factor controlling the composition of the exhaust gases. Low quality diesel fuels cause greater gaseous and smokes emissions, higher noise levels and more difficult cold start-up. Improving the diesel fuels quality in a cost-effective manner is therefore an important issue for industry. ${ }^{1}$ The possible options from a technical and economical viewpoint include upgrading of refining processes, selective blending and using cetane improvers. The use of oxygenated additives for biofuels has been reported as a method to improve the quality of fuels obtained from renewable sources. ${ }^{2-5}$. Oxygenates (e.g. ethers) are usually employed as additives to reduce the CO emissions, soot and soot-related compounds (poly-aromatic hydrocarbons and their nitrated derivates). Commonly used oxygenated additives include alcohols (e.g. methanol, ethanol, isopropyl alcohol, n-butanol and t-butanol) or ethers, such as MTBE, ETBE, TAME, TAEE, THEME, and DIPE. However, during the past decade some of these ethers (e.g. MTBE) have been banned in various states, hence the quest for more sustainable alternatives. There is also an intensive discussion about using linear ethers containing a significantly higher fraction of oxygen, so called oxymethylene dimethylethers, which are high molecular and thus liquid ethers that could be easily produced from methanol. ${ }^{6-8}$ Previous literature reports that linear ethers with over nine carbon atoms showed the best balance between blending cetane number and cold flow properties. ${ }^{1}$ Among them, di-n-pentyl ether (DNPE) is an excellent candidate for diesel fuel formulations due to its high blending cetane number, good cold flow properties and effectiveness in reducing diesel exhaust emissions, particulates and smokes. Moreover, 1butene is an appropriate feedstock for DNPE production, as it can be selectively hydroformylated and hydrogenated to 1-pentanol, which can then be dehydrated to DNPE. Although the literature review reveals several reports on equilibrium and kinetics of DNPE formation by dehydration of 1-pentanol, ${ }^{9-12}$ to the best of our knowledge there is only one study describing a process for DNPE synthesis, based on a membrane reactor. ${ }^{13}$ The present work proposes two new feasible process options for the DNPE production: 1) reaction-separation-recycle process based on an adiabatic reactor, 2) catalytic distillation process. The key design parameters are identified and steady state optimization is performed in Aspen Plus. The objective function is the total annual cost (TAC), which is minimized using key decision variables, such as: reactor size, number of distillation trays, reflux ratio, feed location, and stage catalyst loading. The process alternatives are analyzed in terms of 
energy requirements, total investment, operating cost and annual costs. Furthermore, the controllability is assessed by rigorous dynamic simulation performed in Aspen Dynamics.

\section{Problem statement}

The dehydration of 1-pentanol to yield DNPE is equilibrium limited hence complete reactant conversion is not possible. ${ }^{13}$ As a consequence, reactant separation and recycle are necessary but this should be carried out in an economically efficient manner. Alternatively, the equilibrium displacement can be achieved by removing at least one product from the reaction mixture. The use of a membrane reactor was suggested as a feasible option for in-situ water removal. ${ }^{13}$ Although high reactant conversion is possible, such an option is plagued by the high cost and the reduced service life of the membrane. Moreover, one distillation unit is still necessary for the separation of 1-pentanol and DNPE. As a result, the production cost per unit of DNPE product is currently rather high - about $2.16 \$ / \mathrm{L}$, excluding raw materials ${ }^{13}$ mainly due to the high costs of membrane replacement (25.4 M\$/year) and refrigeration water (13.3 M\$/year). To avoid these problems, we propose here two novel process alternatives for DNPE synthesis, based on reaction-separation-recycle and catalytic distillation, respectively.

\section{Simulation results}

A plant capacity of $26.5 \mathrm{ktpy}$ DNPE is considered in this work. The steady state process simulations and optimization were performed in Aspen Plus, while the controllability was assessed by rigorous dynamic simulation performed in Aspen Dynamics. Both processes (R$\mathrm{S}-\mathrm{R}$ and catalytic distillation) were optimized using the same approach. The optimal values for the real-valued decision variables (such as mass of catalyst, pressure, flow rate, etc.) were found in Aspen Plus using the SQP method. No integer-valued variables are used in the R-S$\mathrm{R}$ case, whereas in case of the catalytic distillation process, a direct search algorithm was used to determine the optimal values for the number of trays, feed tray location, first reacting and last reacting trays.

\subsection{Physical properties and kinetics}

The physical properties (such as boiling points, enthalpy of formation, ideal gas heat capacity, Antoine parameters, molar density, etc) of all components are available in the pure component database of Aspen Plus v8.4. As the process takes place at moderate pressure and involves polar chemical species, only the non-ideality of the liquid phase has to be taken into account. 
1 Accordingly, UNIQUAC was used as a suitable property model for this system. ${ }^{14}$ The Aspen

2 Plus database contains UNIQUAC binary interaction parameters for the water - 1-pentanol

3 pair. The binary interaction parameters for water - DNPE and 1-pentanol - DNPE pairs were

4 estimated by the UNIFAC group contribution method. Estimation of binary interaction

5 parameters by the UNIFAC method was also employed be several other kinetic and

6 thermodynamic studies. ${ }^{1,9-13,17}$

7 In order to design the reaction and separation sections of a plant, one needs to consider the

8 boiling points of pure components and azeotropes that can be found in the ternary system 1-

9 pentanol - water - DNPE (Table 1). DNPE is the high-boiling component hence it can be

10 easily separated. Water is involved in several heterogeneous azeotropes, which suggest the 11 use of a liquid-liquid split in order to cross the distillation boundary. Figure 1 presents the 12 residue curve map ( $\mathrm{RCM})$ and the ternary diagram of this ternary system. Besides the 13 presence of azeotropes, the system also exhibits a liquid-liquid split envelope, which must be 14 accounted for in the design of the separation sequence - as two liquid phases should be 15 avoided inside distillation columns, but a separate decanter could be used for phase splitting.

16 Note that the dehydration of 1-pentanol to yield DNPE is an equilibrium limited reaction:

$$
2 \mathrm{C}_{5} \mathrm{H}_{9}-\mathrm{OH} \rightleftarrows \mathrm{C}_{5} \mathrm{H}_{9}-\mathrm{O}-\mathrm{C}_{5} \mathrm{H}_{9}+\mathrm{H}_{2} \mathrm{O}
$$

(W)

The etherification of 1-pentanol was reported to be catalysed by NaA, H-Beta and ZSM-5 zeolites, eta-alumina, Amberlyst 70 (and other types), Dowex 50Wx4-50, Nafion NR50. 1,9-12, ${ }^{15-17}$ When Amberlyst 70 is used as catalyst, the reaction kinetics is described by the following expression, derived from an Eley-Rideal mechanism: ${ }^{10,13}$

$$
r=\frac{k a_{P}^{2}\left(1-\frac{1}{K_{e q}} \frac{a_{W} a_{D}}{a_{P}^{2}}\right)}{a_{P}\left(1+K_{W} a_{W}^{1 / 2}\right)}
$$

23 where:

$$
k=4.6 \times 10^{-6} \exp \left(-11595\left(\frac{1}{T}-\frac{1}{438}\right)\right) \frac{\mathrm{kmol}}{\mathrm{kg}_{\text {cat }} \cdot \mathrm{s}}
$$

$$
K_{e q}=8.9229 \cdot \exp \left(\frac{778.69}{T}\right)
$$

$$
K_{W}=4.306 \cdot \exp \left(-6616\left(\frac{1}{T}-\frac{1}{438}\right)\right)
$$


1 with temperature $(T)$ expressed in $\mathrm{K}$. This kinetics is used in the present study to allow for a

2 fair comparison of the newly proposed processes against the previously reported membrane 3 reactor for the production of DNPE by etherification in liquid phase. ${ }^{13}$

4 Note that the kinetic experiments performed at temperatures below $150{ }^{\circ} \mathrm{C}$ and involving catalyst particles of different sizes proved that mass transfer does not affect the reaction rate. ${ }^{10}$ Moreover the Arrhenius plots of initial reaction rates are straight lines for temperatures up to $180{ }^{\circ} \mathrm{C} .{ }^{10}$ Thus, it can be concluded that diffusion does not influence the process kinetics over the entire temperature range of interest. This can be explained by the fact that the resin beads swell sufficiently in aqueous medium, allowing good accessibility to inner active centers. ${ }^{10}$

\subsection{Reaction-separation-recycle process}

The reaction is only slightly exothermic and it can be performed in an adiabatic plug-flow reactor. Because the reaction is equilibrium limited, complete reactant conversion is not possible ${ }^{9,13}$ hence the use of a reaction-separation-recycle process can be considered. ${ }^{18,19}$ In a reaction-separation-recycle (R-S-R) plant - flowsheet shown in Figure 2 - the fresh and recycled reactant (1-pentanol) are brought to reaction temperature by means of a processprocess heat exchanger (FEHE), and a heater. The reaction takes place in a catalytic reactor that is operated adiabatically, in a single-phase (liquid). A multi-tubular reactor configuration (with only 25 large tubes) was chosen, as it allows better control of the flow pattern, uniform catalyst arrangement, and better mechanical resistance at the operating pressure (12 bar), when compared with a single large tube. In particular, the multi-tube arrangement leads to a large value of the length-to-diameter ratio, therefore minimizing the axial dispersion. ${ }^{20}$ Note that, through the entire reactor length, the mixture is a one-phase system due to the limited amount of water and high pressure and temperature (exceeding $160{ }^{\circ} \mathrm{C}$ ). Therefore, the kinetics described by equation (2) is applicable.

The pressure of the reactor effluent is reduced to 1.1 bar. The partially vaporized stream is fed to the first distillation column. The distillate, containing the 1-pentanol - water heterogeneous azeotrope is condensed at the boiling temperature of the mixture, then sub-cooled to $30{ }^{\circ} \mathrm{C}$, and sent to the liquid-liquid separation. The low limit of temperature is considered $30{ }^{\circ} \mathrm{C}$ for operating reasons, since cheap cooling water (at $20^{\circ} \mathrm{C}$ ) can be used instead of expensive refrigeration. Obviously, during summer time the temperature could be increased with little impact on the phase splitting. The aqueous phase is withdrawn as product, while the organic phase is returned as reflux to the distillation column. Compared with the membrane process 
1 from literature, ${ }^{13}$ the purity of water is higher: $99.8 \% \mathrm{~mol}$ for R-S-R and catalytic distillation 2 (see next section) versus $94.75 \% \mathrm{~mol}$ in the membrane process. Note that the purity of the 3 water product stream is set by the LLE which is only slightly influenced by the operating 4 temperature in the decanter - if the decanting temperature increases to $60{ }^{\circ} \mathrm{C}$, the water purity is $99.7 \%$ mol. The bottom product of the column contains 1-pentanol and DNPE, and it is sent to the second distillation column. The distillate and bottoms are the 1-pentanol recycle and the DNPE product.

After developing the base case design based on heuristics, the plant design was further optimized using the minimization of the total annual cost (TAC) as objective function:

$$
T A C=O P E X+\frac{C A P E X}{\text { payback period }}
$$

A payback period of 3 years was used, ${ }^{21}$ and it was assumed that the plant is running 8000 hours/year. In addition, the following heating and cooling costs were taken into account: highpressure (HP) steam (42 bar, $\left.254^{\circ} \mathrm{C}, \$ 9.88 / \mathrm{GJ}\right)$, medium-pressure (MP) steam (11 bar, 184 $\left.{ }^{\circ} \mathrm{C}, \$ 8.22 / \mathrm{GJ}\right)$, low-pressure (LP) steam (6 bar, $\left.160{ }^{\circ} \mathrm{C}, \$ 7.78 / \mathrm{GJ}\right)$, and cooling water $(\$ 0.72 / G J)$. Note that the costs of utilities used here are typical for a US plant. ${ }^{21}$ However, the reader must be aware that the costs of utilities might differ, being dependent on the plant location. In case of the reaction-separation-recycle process, MP steam is used for heating the reactor feed to reaction temperature (duty $Q_{\mathrm{H}}$ ), LP steam is used for the reboiler of column 1 (duty $Q_{\mathrm{R} 1}$ ), HP steam is used for the reboiler of column 2 (duty $Q_{\mathrm{R} 2}$ ), and cooling water is used for the condenser of column 1 (duty $Q_{\mathrm{C} 1}$ ).

The total investment costs (CAPEX) include the reactor, distillation columns, FEHE and heater. The cost of the multi-tubular chemical reactor (tubes with diameter $0.3 \mathrm{~m}$ ) and the cost of the heat exchangers (reboiler, condenser, FEHE, heater) are given by: ${ }^{22}$

$$
C_{\text {reactor/HEX }}(U S \$)=(M \& S / 280) \cdot\left(474.7 \cdot A^{0.65}\right)\left(2.29+F_{m}\left(F_{d}+F_{p}\right)\right)
$$

where $M \& S$ is the Marshall $\&$ Swift equipment cost index $(M \& S=1536.5$ in 2012), $A$ is the area $\left(\mathrm{m}^{2}\right), F_{m}=1$ (carbon steel), $F_{d}=0.8$ (fixed-tube), $F_{p}=0$ (less than 20 bar). To calculate the heat transfer area, a heat transfer coefficient $U=500 \mathrm{kcal} / \mathrm{m}^{2} / \mathrm{h} / \mathrm{K}$ was assumed. For the reboilers, the design factor was taken as $F_{d}=1.35$. For the solid catalyst (ion exchange resin, with a bulk density of $770 \mathrm{~kg} / \mathrm{m}^{3}$ ), a purchased cost of $50 \$ / \mathrm{kg}$ was considered. Clearly, the price of catalyst differs per country and manufacturer. While Pera-Titus et al. ${ }^{13}$ used a price of $\$ 20 / \mathrm{kg}$ for a very large amount of catalyst, in this work we consider a higher cost due to inflation and significantly smaller amount of catalysts used (no bulk discounts included). This 
1 price is also in line with other literature references citing up to $\$ 50 / \mathrm{kg}_{\text {catalyst. }}{ }^{21}$

2 The distillation columns diameter $(D)$ were obtained by the tray sizing utility from Aspen

3 Plus, while the height was evaluated as $H=0.6 \cdot(N T-1)+2(\mathrm{~m})$. Afterwards, the cost of the

4 columns shell was calculated as: ${ }^{22}$

$5 \quad C_{\text {shell }}(U S \$)=(M \& S / 280) \cdot\left(957.9 \cdot D^{1.066} \cdot H^{0.82}\right) \cdot\left(2.18+F_{c}\right)$

where $F_{\mathrm{c}}=F_{m} \cdot F_{p}, F_{m}=1$ (carbon steel) and $F_{p}=1+0.0074 \cdot(P-3.48)+0.00023 \cdot(P-3.48)^{2}$

7 The cost of the trays was given by:

$C_{\text {trays }}(U S \$)=N_{T} \cdot(M \& S / 280) \cdot 97.2 \cdot D^{1.55} \cdot\left(F_{t}+F_{m}\right)$

with $F_{t}=0$ (sieve trays) and $F_{m}=1$ (carbon steel)

The optimization was carried out using the state of the art sequential quadratic programming (SQP) method available in Aspen Plus. Backed by a solid theoretical and computational foundation, the SQP method has become one of the most successful methods for solving nonlinearly constrained optimization problems. ${ }^{23}$ The decision variables considered for the optimization procedure are:

- Temperature at the HEATER outlet / reactor inlet, $T_{r, i n}$ :

$$
100{ }^{\circ} \mathrm{C}<T_{r, \text { in }}<190{ }^{\circ} \mathrm{C}
$$

- Distillate to feed ratio $(D / F)$ of column CoL-1

$0.2<D / F<0.95$

A design-specification block was implemented, in which the controlled variable was the mole purity of the DNPE product stream, $x_{\mathrm{DNPE}}=0.999$ and the manipulated variable was the column CoL-2 distillate rate, $10 \mathrm{kmol} / \mathrm{h}<D_{2}<100 \mathrm{kmol} / \mathrm{h}$. Additionally, an inequality constraint set an upper limit on the reaction temperature (required to avoid catalyst deactivation), $T_{\max , \text { ReActor }}<180{ }^{\circ} \mathrm{C}$. The number of trays for the two columns was set to 9 , with feed on tray 5 and 1, respectively. By performing several optimization runs, it was found that the total annual cost (TAC) is practically insensitive to these values, the cost of using more trays being compensated by smaller reboiler duties. Moreover, adding a condenser to the last distillation column (COL-2) does not improve the objective function, as the additional equipment and energy costs overcome the positive effect that the high-purity recycle has on the reaction rate. Because COL-2 has only one degree of freedom (the vapor boilup, or equivalently, the distillate rate) - which was used to ensure that the DNPE product has the required purity - the recycle flow rate (same as the distillate) is not available for optimization. Note that using more trays in the columns leads to slightly reduced energy costs but larger investment costs. The feed location stage of Column 1 was determined by matching the stage 
1 composition with the feed stream. Column 2 is operated as a stripping column with no condenser and no reflux hence the feed location stage is stage 1. Figure 2 presents the detailed stream results, together with a summary of the units design, whereas Table 2 provides the optimal design parameters. The reactor accounts for the main investment cost $(533 \mathrm{k} \$$, including $352 \mathrm{k} \$$ for the catalyst), while the costs of distillation columns COL-1 and COL-2 are $151 \mathrm{k} \$$ and $89 \mathrm{k} \$$, respectively. Note that the main cost of the reactor (over 75\%) is represented by the catalyst and not by the (low number of) tubes, as it can be inferred from Table 2. The operating costs are mainly given by the steam used in the two reboilers and heater: $40.7 \mathrm{k} \$ /$ year, $102 \mathrm{k} \$ /$ year and $48.9 \mathrm{k} \$ /$ year, respectively.

The control structure (shown in Figure 2, details in Table 3) fixes the plant-inlet flow of 1pentanol, allowing the direct manipulation of the plant throughput. ${ }^{24}$ The heater duty controls the reactor-inlet temperature. Control of the first distillation column involves sump level, pressure and a temperature on the stripping section (stage 8), by means of bottoms flow, vapour distillate flow and reboiler duty. Condenser duty sets the temperature of the liquidliquid separator. Finally, the organic reflux and water product flow rates control the levels of the organic and aqueous phases. Control loops of the second distillation column are: distillate rate - pressure, bottoms flow rate - level of the column sump, and reboiler duty - temperature on the lower part of the column (stage 8). Note that stage 8 was determined as the sensitive stage, based on the temperature profile in the column. For both distillation columns, the control structures (pairing of the controlled and manipulated variables) are standard and widely used in industry. ${ }^{25}$ A dynamic simulation was built in Aspen Dynamics. All vessels were sized assuming a residence time of 15 minutes. This value is in line with the rules of thumb accepted industrially (5-20 min) and suggested in numerous references. ${ }^{14,20,25}$ The controllers were chosen as PI and were tuned by the direct-synthesis method. According to this method, the desired closed-loop response for a given input is specified. Then, with the model of the process known, the required form and the tuning of the feedback controller are back-calculated. For all controllers, the acceptable control error $\left(\Delta \varepsilon_{\max }\right)$ and the maximum available control action $\left(\Delta u_{\max }\right)$ were specified. Then the controller gain, expressed in engineering units, was calculated as $K_{\mathrm{c}}=\Delta u_{\max } / \Delta \varepsilon_{\max }$ and translated into percentage units. First order open-loop models were assumed, in order to calculate the reset time of the pressure and temperature control loops. As rough evaluations of the process time constants $(\tau), 12 \mathrm{~min}$ and 20 min were used, respectively. It can be shown that the direct synthesis method requires that the reset time of a PI controller is equal to the time constant of the process $\left(\tau_{\mathrm{i}}=\tau\right) \cdot{ }^{26}$ For 
1 the level controllers, a large reset time $\tau_{\mathrm{i}}=60 \mathrm{~min}$ was chosen as no tight control is required.

2 Table 3 presents the details of the control loops and controller tuning, while the results of 3 dynamic simulation are given in Figure 3. The simulation starts from steady state. At time $t=$

$42 \mathrm{~h}$, the plant inlet flow rate is increased by $20 \%$, from $42 \mathrm{kmol} / \mathrm{h}$ to $50 \mathrm{kmol} / \mathrm{h}$. As more reactant is fed to the plant, the production rate increases from $21 \mathrm{kmol} / \mathrm{h}$ to $25 \mathrm{kmol} / \mathrm{h}$ in about 6 hours. The purities of DNPE and water products remain practically unchanged. Only one case is presented here due to space limitations. Other disturbances were tested as well, with similar performance: $20 \%$ decrease of the production rate, $10 \%$ decrease of the FEHE heat transfer coefficient (for example due to fouling), increase of the distillation columns operating pressure from 1 bar to 1.1 bar.

\subsection{Catalytic distillation process}

The use of advanced distillation technologies - including reactive and catalytic distillation in the production of biofuels and additives have been recently reported in the case of esterification and etherification reactions. ${ }^{27-31}$ In this work we propose a process for DNPE production based on catalytic distillation, as a process intensification method that is used to perform both reaction and separation in the same unit. According to the feasibility framework proposed in literature, ${ }^{32}$ reactive distillation is a good candidate for DNPE synthesis, as the reactant is the middle boiling component in the water / 1-pentanol / DNPE mixture.

The process flowsheet is schematically shown in Figure 4. The reactant is fed at the top of the reactive section, as saturated liquid stream. High purity (over 99.9\%) DNPE is obtained as bottom product, while the vapor distillate is condensed and sent to liquid-liquid separation, which gives the water product and the organic reflux. It is worth noting that the same ionexchange resin catalyst is used in the catalytic distillation, just as in the R-S-R process and the membrane reactor reported earlier. ${ }^{13}$ MellaPak structured packing is used to enclose the solid catalyst in between the sandwiched sheets of packing - similar to the KataPak-SP structured packing especially developed by Sulzer for reactive distillation systems.

After developing the base case design, the reactive distillation column was further optimized using the minimization of the total annual cost as objective function (as described earlier). The investment cost (CAPEX) included the cost of the column shell, reboiler and condenser (as described earlier), as well as the structured packing (MellaPak, cost 10,000 $\$ / \mathrm{m}^{3}$ ) and the solid catalyst. The operating cost (OPEX) included the cost of high-pressure steam and cooling water. The decision variables considered for the optimization procedure are: 
- Total column stages, $N_{T}$

- Feed stage, $N_{F}$

- First reactive stage, $N_{R 1}$

- $\quad$ Last reactive stage, $N_{R 2}$

- Vapor distillate rate, $D$

- Operating pressure, $P$ $10<D<100 \mathrm{kmol} / \mathrm{h}$

- Amount of catalyst on each reactive stage, $m_{\text {cat }}$ $1<P<5$ bar $20<m_{\text {cat }}<200 \mathrm{~kg}$ The problem constraints are related to the minimum product purity $\left(x_{\mathrm{DNPE}}>0.999\right)$, the maximum temperature of the reactive stages $\left(T_{k}<180{ }^{\circ} \mathrm{C}, k=N_{R 1}, \ldots N_{R 2}\right)$, and the volume fraction of the catalyst per stage $(\omega<0.2)$. An inner loop used the Optimization tool of AspenTech Aspen Plus to find the real-valued decision variables $\left(D, P, m_{c a t}\right)$, while ensuring that the constraints are satisfied. The integer-valued variables $\left(N_{T}, N_{F}, N_{R 1}, N_{R 2}\right)$ were found in an outer loop, where a direct search algorithm was implemented in MathWorks Matlab. Aspen Plus and Matlab exchanged data via a COM interface. It is also worth noting that optimizing a chemical process is typically a mixed-integer nonlinear problem that is nonconvex and likely to have multiple locally optimal solutions. Such problems are intrinsically very difficult to solve, and the solution time increases rapidly with the number of variables and constraints. A theoretical guarantee of convergence to the globally optimal solution is not possible for non-convex problems.

Figure 4 presents the process flowsheet, mass balance, as well as the process control structure, while Table 4 provides the key parameters of the optimized RD design. The catalytic distillation column has an investment cost of $816 \mathrm{k} \$$, and operating costs of $251 \mathrm{k} \$$ /year, leading to a total annual cost of $523 \mathrm{k} \$ /$ year. In addition, Figure 5 shows the composition, as well as temperature and reaction rate profiles along the catalytic distillation column - for the optimal design case. It can be observed that the high purity DNPE is obtained as bottom product, while a mixture of 1-pentanol and water is removed as top product of the column. According to the VLE, the range of temperature values on reactive stages is $140-180{ }^{\circ} \mathrm{C}$. The reaction rate is quite low on the top 10 reactive stages, but increases towards the bottom of the column. On the reactive stages, the liquid phase mole fraction of 1-pentanol is quite high exceeding 0.6.

Furthermore, Figure 6 presents the key results of the dynamic simulations for the DNPE production in a catalytic distillation column. Details of the control loops and controller tuning are given in Table 5. At time $\mathrm{t}=2 \mathrm{~h}$, the flow rate of fresh 1-pentanol is increased by $20 \%$, 
1 from $42 \mathrm{kmol} / \mathrm{h}$ to $50 \mathrm{kmol} / \mathrm{h}$. As more reactant is fed to the plant, the production rate

2 increases to the setpoint while the purities of DNPE and water products remain practically

3 unchanged. Remarkable, the system is able to reject the disturbance, with short response time and low overshooting. Note that similar results were obtained when the reactor-inlet flow rate of fresh 1-pentanol was decreased, with the result of lower production rate $(-20 \%)$.

\section{Process comparison}

Table 6 presents the key performance indicators of the two processes proposed. Compared with the reported process based on membrane reactor, ${ }^{13}$ both processes described here have greatly reduced total investment and operating costs. Remarkably, the R-S-R process appears to be slightly more attractive than the RD process alternative. This result can be explained by the fact that catalytic distillation is somewhat limited by constraints, such as a common operation range for distillation and reaction (similar temperature and pressure). Working in the limited overlapping window of operating conditions (reaction and separation) is not always the optimal solution, but merely a trade-off. On the contrary, in a conventional multiunit flowsheet (such as a R-S-R process), the reactors can be operated at their optimum parameters that are most favorable for the chemical kinetics, while the distillation columns can be operated at their optimal pressures and temperatures where the vapor-liquid equilibrium (VLE) properties are the most favorable for separation.

Having said that, in case of the DNPE process the operating window for reaction is limited to the temperature range $120-180{ }^{\circ} \mathrm{C}$ due to minimum acceptable reaction rate and maximum temperature at which the solid catalyst is active and stable, while pressure must have values that allow a liquid or vapor-liquid operation. These limits are shown in Figure 7 by the REACTION area. The optimal reaction conditions are at $180{ }^{\circ} \mathrm{C}$ and $\min .2 .1$ bar, where the reaction rate is highest and maximum conversion is possible. Similarly, the separation by distillation is limited by the temperature range of $45-245{ }^{\circ} \mathrm{C}$ which allows condensation with cooling water and heating with high-pressure steam. The corresponding pressure range is therefore 0.1-3.6 bar - according to the VLE, such that vapor-liquid phases exist. The temperature limits are shown in Figure 7 by the DisTILLATION area. As vacuum distillation incurs additional costs, the optimal separation should be performed at atmospheric pressure, when the range of boiling points is $100-187^{\circ} \mathrm{C}$. As the reaction is only slightly exothermic, in the R-S-R process the reactor feed can be at a rather high temperature $\left(160{ }^{\circ} \mathrm{C}\right)$, without violating the maximum temperature constraint $\left(180^{\circ} \mathrm{C}\right)$. Therefore, the reaction takes place in 
1 the range $160-180{ }^{\circ} \mathrm{C}$ which ensures a reaction rate close to the maximum achievable one. On

2 the other hand, the separation is performed at atmospheric pressure, therefore at the optimal 3 conditions. In the Reactive Distillation process, operation at a higher pressure is necessary in 4 order to have a temperature range for which the reaction rate is high. However, the higher pressure has a detrimental effect of relative volatilities, and therefore on separation efficiency. Moreover, as water mole fraction increases towards the top of the column, the temperature range on the reactive stages is $140-180{ }^{\circ} \mathrm{C}$, with the result of rather low reaction rate on the first 10 reactive stages (Figure 5). In conclusion, there is no clear overlap of the optimal conditions for both reaction and distillation. As a convenient visual aid, Figure 7 illustrates graphically the overlapping window of operating parameters (temperature and pressure) for both reaction and distillation operations - the optimal operating range is the area marked by REACTIVE DISTILLATION.

\section{Conclusions}

Compared with the membrane reactor previously reported in literature, both alternatives (conventional reaction-separation-recycle process and compact catalytic distillation) proposed here are better DNPE process candidates, requiring lower operating costs and simpler units leading to much smaller investment costs, while also having good controllability. The reaction-separation-recycle process allows designing both the reactor and the separation units to operate close to the optimal conditions of reaction and distillation, respectively. Hence the reaction-separation-recycle process appears to be slightly more attractive than the catalytic distillation process, which operates in the overlapping window of process conditions for reaction and distillation, and thus suffering from this inherent trade-off.

\section{Acknowledgment}

The financial support provided to Romuald György by the Sectoral Operational Programme Human Resources Development, financed from the European Social Fund and by the Romanian Government under the contract POSDRU/156/1.2/G/135764 „Improvement and implementation of universitary master programs in the field of Applied Chemistry and Materials Science - ChimMaster", as well as the financial support provided to the co-authors from Mexico by Universidad de Guanajuato and CONACyT (Mexico), is gratefully acknowledged. 


\section{$1 \quad$ References}

1. Tejero J, Fite C, Iborra M, Izquierdo JF, Cunill F and Bringue R, Liquid-phase dehydrocondensation of 1-pentanol to di-n-pentyl ether (DNPE) over medium and large pore acidic zeolites, Micropor. Mesopor. Mat. 117: 650-660 (2009).

2. Qi DH, Chen H, Geng LM and Bian YZ, Effect of diethyl ether and ethanol additives on the combustion and emission characteristics of biodiesel-diesel blended fuel engine, Renew. Energy 36: 1252-1258 (2011).

3. Happonen M, Heikkila J, Aakko-Saksa P, Murtonen T, Lehto K, Rostedt A, Sarjovaara T, Larmi M, Keskinen $\mathrm{J}$ and Virtanen A, Diesel exhaust emissions and particle hygroscopicity with HVO fuel-oxygenate blend, Fuel 103: 380-386 (2013).

4. Vlad E, Bildea CS and Bozga G, Robust optimal design of a glycerol etherification process, Chem. Eng. Technol. 36: 251-258 (2013).

5. Nandiwale KY, Patil SE and Bokade VV, Glycerol etherification using n-butanol to produce oxygenated additives for biodiesel fuel over h-beta zeolite catalysts, Energy Technol. 2: 446-452 (2014).

6. Burger J, Siegert M, Ströfer E and Hasse H, Poly(oxymethylene) dimethyl ethers as components of tailored diesel fuel: Properties, synthesis and purification concepts. Fuel 89: $3315-3319$ (2010).

7. Natarajan M, Frame EA, Naegeli DW, Asmus T, Clark W, Garbak J, Manuel A, Gonzalez D, Liney E, Piel W and Wallace JP, Oxygenates for advanced petroleum-based diesel fuels: Part 1. Screening and selection methodology for oxygenates, SAE Paper No. 200101-3631 (2001).

8. Lumpp B, Rothe D, Pastötter C, Lämmermann R and Jacob E, Oxymethylene ethers as diesel fuel additives of the future, MTZ worldwide eMagazine 72(3): 34-38 (03/2011).

9. Bringue R, Tejero J, Iborra M, Izquierdo JF, Fite C and Cunill F, Experimental study of the chemical equilibria in the liquid-phase dehydration of 1-pentanol to di-n-pentyl ether, Ind. Eng. Chem. Res. 46: 6865-6872 (2007).

10. Bringue R, Iborra M, Tejero J, Izquierdo JF, Cunill F, Fite C and Cruz V, Thermally stable ion-exchange resins as catalysts for the liquid-phase dehydration of 1-pentanol to di-n-pentyl ether (DNPE), J. Catal. 244: 33-42 (2006).

11. Bringue R, Ramirez E, Fite C, Iborra M, and Tejero J, Kinetics of 1-pentanol etherification without water removal, Ind. Eng. Chem. Res. 50: 7911-7919 (2011).

12. Tejero J, Fite C, Iborra M, Izquierdo JF, Bringue R and Cunill F, Dehydration of 1- 
pentanol to di-n-pentyl ether catalyzed by a microporous ion-exchange resin with simultaneous water removal, Appl. Catal. A-Gen. 308: 223-230 (2006).

13. Pera-Titus M, Llorens J. and Cunill F, Technical and economical feasibility of zeolite $\mathrm{NaA}$ membrane-based reactors in liquid-phase etherification reactions, Chem. Eng. Process. 48: 1072-1079 (2009).

14. Kiss AA, Distillation technology - Still young and full of breakthrough opportunities, $J$. Chem. Technol. Biot. 89: 479-498 (2014).

15. Nel RJJ and de Klerk A, Dehydration of C5-C12 linear 1-alcohols over eta-alumina to fuel ethers, Ind. Eng. Chem. Res. 48: 5230-5238 (2009).

16. Mohamed MM and Al-Esaimi MM, Synergistic catalysis effect in pentanol conversion into di-n-pentyl ether on ZSM-5 supported titania catalysts synthesized by sol-gel, Mat. Chem. Phys. 115: 209-216 (2009).

17. Casas C, Bringue R, Ramirez E, Iborra M and Tejero J, Liquid-phase dehydration of 1octanol, 1-hexanol and 1-pentanol to linear symmetrical ethers over ion exchange resins, Appl. Catal. A-Gen. 396: 129-139 (2011).

18. Kiss AA, Bildea CS and Dimian AC, Design and control of recycle systems by non-linear analysis, Comput. Chem. Eng. 31: 601-611 (2007).

19. Dimian AC, Bildea CS and Kiss AA, Integrated design and simulation of chemical processes, $2^{\text {nd }}$ edition, Elsevier, Amsterdam, 2014.

20. Levenspiel O, Chemical reaction engineering, John Wiley \& Sons, New York, 1999.

21. Luyben WL, Principles and case studies of simultaneous design, AiChE Wiley, Hoboken, 2011.

22. Turton R, Bailie RC, Whiting WB and Shaeiwitz JA, Analysis, synthesis and design of chemical processes, 3rd edition, Prentice Hall, USA, Appendix A, 2009.

23. Boggs PT and Tolle JW, Sequential quadratic programming, Acta Numerica, 4: 1-51 (1995)

24. Bildea CS, Dimian AC, Fixing flow rates in recycle systems: Luyben's rule revisited, Ind. Eng. Chem. Res. 42: 4578-4585 (2003).

25. Luyben WL, Distillation design and control using Aspen simulation, Wiley, 2006.

26. Luyben WL and Luyben ML, Essentials of process control, McGraw-Hill, 1997.

27. Kiss AA, Novel applications of dividing-wall column technology to biofuel production processes, J. Chem. Technol. Biot. 88: 1387-1404 (2013).

28. Kiss AA and Bildea CS, A review on biodiesel production by integrated reactive 
1 separation technologies, J. Chem. Technol. Biot. 87: 861-879 (2012).

2 29. Kiss AA and Suszwalak DJPC, Innovative dimethyl ether synthesis in a reactive dividingwall column, Comput. Chem. Eng. 38: 74-81 (2012).

4 30. Shah M, Kiss AA, Zondervan E, and de Haan AB, Evaluation of configuration 5 alternatives for multi-product polyester synthesis by reactive distillation, Comput. Chem. $6 \quad$ Eng. 52: 193-203 (2013).

7 31. Patrut C, Bildea CS and Kiss AA, Catalytic cyclic distillation - A novel process 8 intensification approach in reactive separations, Chem. Eng. Process. 81: 1-12 (2014).

9 32. Shah M, Kiss AA, Zondervan E, and de Haan AB, A systematic framework for the 10 feasibility and technical evaluation of reactive distillation processes, Chem. Eng. Process. 11 60: 55-64 (2012). 


\section{Tables}

2

3 Table 1. Singular points in the 1-pentanol - water- DNPE system (UNIQUAC)

\begin{tabular}{l|r|r|l}
\hline $\begin{array}{l}\text { Component / azeotrope } \\
\text { (mol fraction composition) }\end{array}$ & $\begin{array}{r}\text { Boiling point } \\
\text { (at } 1.0 \text { bar) }\end{array}$ & $\begin{array}{r}\text { Boiling point } \\
\text { (at } 1.5 \text { bar) }\end{array}$ & Node type \\
\hline $\begin{array}{l}\text { Ternary azeotrope, heterogeneous: 1-pentanol } \\
\text { (0.115); Water (0.8732); DNPE (0.0116) }\end{array}$ & $96.37{ }^{\circ} \mathrm{C}$ & $107.36{ }^{\circ} \mathrm{C}$ & unstable node \\
Binary azeotrope, heterogeneous & $96.41^{\circ} \mathrm{C}$ & $107.40{ }^{\circ} \mathrm{C}$ & saddle \\
1-pentanol (0.126); Water (0.874) & $98.7^{\circ} \mathrm{C}$ & $109.93{ }^{\circ} \mathrm{C}$ & saddle \\
Binary azeotrope, heterogeneous & $100{ }^{\circ} \mathrm{C}$ & $111.4{ }^{\circ} \mathrm{C}$ & stable node \\
Water (0.9539); DNPE (0.00461) & $137.8^{\circ} \mathrm{C}$ & $150.34{ }^{\circ} \mathrm{C}$ & saddle \\
Water & $186.75{ }^{\circ} \mathrm{C}$ & $202.39{ }^{\circ} \mathrm{C}$ & stable node \\
1-pentanol & & \\
Di-n-pentyl ether (DNPE) &
\end{tabular}


2 Table 2. Design of the DNPE plant (reaction-separation-recycle). The optimal values of the 3 decision variables are presented in bold.

4

\begin{tabular}{|c|c|c|}
\hline Reactors & \multicolumn{2}{|c|}{ REACTOR } \\
\hline Inlet temperature $/\left[{ }^{\circ} \mathrm{C}\right]$ & \multicolumn{2}{|c|}{161.0} \\
\hline Pressure / [bar] & \multicolumn{2}{|c|}{12} \\
\hline Number of tubes ( $0.3 \mathrm{~m}$ diameter $)$ & \multicolumn{2}{|c|}{25} \\
\hline Length / [m] & \multicolumn{2}{|c|}{5.04} \\
\hline Amount of catalyst / $[\mathrm{kg}]$ & \multicolumn{2}{|c|}{7760} \\
\hline Installed cost / [k\$] & \multicolumn{2}{|c|}{522.03} \\
\hline Separation columns & COL-1 & COL-2 \\
\hline Number of trays & 9 & 9 \\
\hline Feed tray & 5 & 1 \\
\hline Reflux rate / $[\mathrm{kmol} / \mathrm{h}]$ & 10.41 & - \\
\hline Distillate : Feed ratio & 0.4207 & 0.517 \\
\hline Diameter / [m] & 0.44 & 0.66 \\
\hline Reboiler duty / [kW] & 118.40 & 408.29 \\
\hline Condenser duty / [kW] & 411.75 & - \\
\hline Installed cost / [k\$] & 163.81 & 99.43 \\
\hline Utilities / [k\$ / year] & 50.3 & 10.26 \\
\hline Heat exchangers & FEHE & HEATER \\
\hline Pressure / [bar] & 1 & 1 \\
\hline Heat duty / [kW] & 296.5 & 206.7 \\
\hline Heat transfer area $/\left[\mathrm{m}^{2}\right]$ & 9.47 & 8.38 \\
\hline Installed cost / [k\$] & 31.95 & 31.95 \\
\hline Utilities / [k\$ / year $]$ & - & 47.34 \\
\hline
\end{tabular}


2 Table 3. Controller tuning parameters for the plantwide control of a DNPE plant (R-S-R)

\begin{tabular}{|c|c|c|c|c|}
\hline Controller & $P V$, value \& range & $O P$, value \& range & $K_{c}, \% / \%$ & $T_{i}, \min$ \\
\hline \multicolumn{5}{|l|}{ HEATER } \\
\hline TC & $\begin{array}{l}\text { Temperature }=161^{\circ} \mathrm{C} \\
150 \ldots 170^{\circ} \mathrm{C}\end{array}$ & $\begin{array}{l}\text { Duty }=0.173 \times 10^{6} \mathrm{kcal} / \mathrm{h} \\
0 \ldots 1 \times 10^{6} \mathrm{kcal} / \mathrm{h}\end{array}$ & 1 & 20 \\
\hline \multicolumn{5}{|l|}{ COL-1 } \\
\hline PC & $\begin{array}{l}\text { Inlet pressure }=1.1 \mathrm{bar} \\
0.9 \ldots 1.1 \mathrm{bar}\end{array}$ & $\begin{array}{l}\text { Valve opening }=50 \% \\
0 \ldots 100 \%\end{array}$ & 1 & 5 \\
\hline PC & $\begin{array}{l}\text { Pressure }=1 \text { bar } \\
0.95 \ldots 1.05 \text { bar }\end{array}$ & $\begin{array}{l}\text { Vapour distillate }=31.28 \mathrm{kmol} / \mathrm{h} \\
0 \ldots 62.5 \mathrm{kmol} / \mathrm{h}\end{array}$ & 1 & 12 \\
\hline TC & $\begin{array}{l}\text { Stage } 9 \text { temperature }=123.4^{\circ} \mathrm{C} \\
1110 \ldots 140{ }^{\circ} \mathrm{C}\end{array}$ & $\begin{array}{l}\text { Reboiler duty }=0.151 \times 10^{6} \mathrm{kcal} / \mathrm{h} \\
0 \ldots 0.3 \times 10^{6} \mathrm{kcal} / \mathrm{h}\end{array}$ & 1 & 20 \\
\hline TC & $\begin{array}{l}\text { Condensate temperature }=30^{\circ} \mathrm{C} \\
20 \ldots 40^{\circ} \mathrm{C}\end{array}$ & $\begin{array}{l}\text { Cooling duty }=-0.37 \times 10^{6} \mathrm{kcal} / \mathrm{h} \\
-0.74 \times 10^{6} \ldots 0 \mathrm{kcal} / \mathrm{h}\end{array}$ & 1 & 20 \\
\hline $\mathbf{L C}$ & $\begin{array}{l}\text { Level, organic phase }=0.94 \mathrm{~m} \\
0.4 \ldots 1.8\end{array}$ & $\begin{array}{l}\text { Reflux }=714.3 \mathrm{~kg} / \mathrm{h} \\
0 \ldots 1430 \mathrm{~kg} / \mathrm{h}\end{array}$ & 1 & 60 \\
\hline LC & $\begin{array}{l}\text { Level, aqueous phase }=0.35 \mathrm{~m} \\
0 \ldots 0.8 \mathrm{~m}\end{array}$ & $\begin{array}{l}\text { Water product }=382 \mathrm{~kg} / \mathrm{h} \\
0 \ldots 765 \mathrm{~kg} / \mathrm{h}\end{array}$ & 1 & 60 \\
\hline $\mathbf{L C}$ & $\begin{array}{l}\text { Level, sump }=1.375 \mathrm{~m} \\
0 \ldots 2.75 \mathrm{~m}\end{array}$ & $\begin{array}{l}\text { Bottoms product }=5594 \mathrm{~kg} / \mathrm{h} \\
0 \ldots 11200 \mathrm{~kg} / \mathrm{h}\end{array}$ & 1 & 60 \\
\hline \multicolumn{5}{|l|}{ COL-2 } \\
\hline $\mathbf{P C}$ & $\begin{array}{l}\text { Pressure }=1 \text { bar } \\
0.95 \ldots 1.05 \text { bar }\end{array}$ & $\begin{array}{l}\text { Vapour distillate }=22.47 \mathrm{kmol} / \mathrm{h} \\
0 \ldots 80 \mathrm{kmol} / \mathrm{h}\end{array}$ & 1 & 12 \\
\hline $\mathbf{L C}$ & $\begin{array}{l}\text { Sump level }=1.375 \mathrm{~m} \\
0 \ldots 2.75 \mathrm{~m}\end{array}$ & $\begin{array}{l}\text { Bottoms product }=3321 \mathrm{~kg} / \mathrm{h} \\
0 \ldots 6640 \mathrm{~kg} / \mathrm{h}\end{array}$ & 1 & 60 \\
\hline TC & $\begin{array}{l}\text { Stage } 8 \text { temperature }=178.11^{\circ} \mathrm{C} \\
160 \ldots 190{ }^{\circ} \mathrm{C}\end{array}$ & $\begin{array}{l}\text { Reboiler duty }=0.321 \times 10^{6} \mathrm{kcal} / \mathrm{h} \\
0 \ldots 1 \times 10^{6} \mathrm{kcal} / \mathrm{h}\end{array}$ & 1 & 20 \\
\hline
\end{tabular}


2 Table 4. Design of the DNPE plant (catalytic distillation). The optimal values of the decision 3 variables are presented in bold.

\begin{tabular}{lc}
\hline Parameter [unit] & RDC \\
\hline 1-pentanol temperature / $\left[{ }^{\circ} \mathrm{C}\right]$ & 25 \\
Condenser pressure / [bar] & $\mathbf{2 . 8 2}$ \\
Bottoms pressure / [bar] & 2.93 \\
Number of trays & $\mathbf{5 8}$ \\
Feed tray number & $\mathbf{4}$ \\
First reactive tray & $\mathbf{4}$ \\
Last reactive tray & $\mathbf{5 3}$ \\
Diameter / [m] diameter $)$ & 0.94 \\
Amount of catalyst / $[\mathrm{kg} /$ stage] & $\mathbf{6 3 . 1 5}$ \\
Reboiler duty / $[\mathrm{kW}]$ & $\mathbf{2 9 . 5 7 5}$ \\
Condenser duty / $[\mathrm{kW}]$ & 425.4 \\
Installed cost / [k\$] & 816.35 \\
Utilities / $[\mathrm{k} \$$ / year] & 251.23
\end{tabular}


2 Table 5. Controller tuning parameters for the DNPE plant based on catalytic distillation 3

\begin{tabular}{|c|c|c|c|c|}
\hline Controller & $P V$, value \& range & $O P$, value \& range & $K_{c}, \% / \%$ & $T_{i}, \min$ \\
\hline $\mathbf{P C}$ & $\begin{array}{l}\text { Pressure }=2.82 \text { bar } \\
2.5 \ldots 3.0 \text { bar }\end{array}$ & $\begin{array}{l}\text { Vapour distillate }=34.67 \mathrm{kmol} / \mathrm{h} \\
0 \ldots 57.19 \mathrm{kmol} / \mathrm{h}\end{array}$ & 2 & 12 \\
\hline TC & $\begin{array}{l}\text { Stage } 56 \text { temperature }=219^{\circ} \mathrm{C} \\
210 \ldots 230^{\circ} \mathrm{C}\end{array}$ & $\begin{array}{l}\text { Reboiler duty }=0.866 \times 10^{6} \mathrm{kcal} / \mathrm{h} \\
0 \ldots 1.4 \times 10^{6} \mathrm{kcal} / \mathrm{h}\end{array}$ & 1 & 20 \\
\hline TC & $\begin{array}{l}\text { Condensate temperature }=30^{\circ} \mathrm{C} \\
20 \ldots 40^{\circ} \mathrm{C}\end{array}$ & $\begin{array}{l}\text { Cooling duty }=-0.428 \times 10^{6} \mathrm{kcal} / \mathrm{h} \\
-0.7 \times 10^{6} \ldots 0 \mathrm{kcal} / \mathrm{h}\end{array}$ & 1 & 20 \\
\hline $\mathbf{L C}$ & $\begin{array}{l}\text { Level, organic phase }=1.87 \mathrm{~m} \\
0.0 \ldots 3.75\end{array}$ & $\begin{array}{l}\text { Reflux }=638.9 \mathrm{~kg} / \mathrm{h} \\
0 \ldots 1046 \mathrm{~kg} / \mathrm{h}\end{array}$ & 10 & 60 \\
\hline $\mathbf{L C}$ & $\begin{array}{l}\text { Level, aqueous phase }=0.79 \mathrm{~m} \\
0 \ldots 3.75 \mathrm{~m}\end{array}$ & $\begin{array}{l}\text { Water product }=454.8 \mathrm{~kg} / \mathrm{h} \\
0 \ldots 752 \mathrm{~kg} / \mathrm{h}\end{array}$ & 10 & 60 \\
\hline $\mathbf{L C}$ & $\begin{array}{l}\text { Level, sump }=2.175 \mathrm{~m} \\
0 \ldots 4.35 \mathrm{~m}\end{array}$ & $\begin{array}{l}\text { Bottoms product }=3953.1 \mathrm{~kg} / \mathrm{h} \\
0 \ldots 6650 \mathrm{~kg} / \mathrm{h}\end{array}$ & 1 & 60 \\
\hline
\end{tabular}

5

6

7

8

9

10

11

Table 6. Process comparison in terms of key performance indicators

\begin{tabular}{lcc}
\hline Key performance indicator & R-S-R process & Catalytic distillation \\
\hline Total investment costs, TIC $(\mathrm{k} \$)$ & 842.02 & 816.34 \\
Total operating costs, TOC $(\mathrm{k} \$ / \mathrm{yr})$ & 200.7 & 251.2 \\
Total annual costs, TAC $(\mathrm{k} \$ / \mathrm{yr})$ & 481.4 & 523.3 \\
Specific production cost $(\$ /$ ton DNPE) & 18.2 & 19.7 \\
Energy requirements $(\mathrm{kWh} /$ ton DNPE) & 225 & 256.6 \\
\hline
\end{tabular}

13

14 Note: The following economic figures were reported for the membrane reactor in Pera-Titus 15 et al., ${ }^{13}$ OPEX includes: $25.4 \mathrm{M} \$ / \mathrm{yr}$ for membranes, $13.3 \mathrm{M} \$ / \mathrm{yr}$ for refrigeration, $1.3 \mathrm{M} \$ / \mathrm{yr}$ 16 for cooling water, and $3.8 \mathrm{M} \$ / \mathrm{yr}$ for steam, and $0.2 \mathrm{M} \$ / \mathrm{yr}$ for the catalyst. The equipment 


\section{$1 \quad$ Figure captions (auto-updated)}

3 Figure 1. Residue curve map (RCM) and ternary diagram for the ternary mixture n-pentanol 4 water-DNPE (at $1.5 \mathrm{~atm}$ )

5

6 Figure 2. Flowsheet and plantwide control of a DNPE plant (reaction-separation-recycle) 7

8 Figure 3. Results of the dynamic simulations for the DNPE production in a reaction-

9 separation-recycle process (at time $\mathrm{t}=2 \mathrm{~h}$, the flow rate of fresh 1-pentanol is increased by

$1020 \%$, from $42 \mathrm{kmol} / \mathrm{h}$ to $50 \mathrm{kmol} / \mathrm{h}$ ) - Labels represent stream names from Figure 2.

12 Figure 4. Flowsheet and control of a catalytic distillation process for DNPE production 13

14 Figure 5. Profiles along the catalytic distillation column

Figure 6. Results of the dynamic simulations for the DNPE production in a catalytic

17 distillation column: at time $\mathrm{t}=2 \mathrm{~h}$, the flow rate of fresh 1-pentanol is increased by $20 \%$, from $1842 \mathrm{kmol} / \mathrm{h}$ to $50 \mathrm{kmol} / \mathrm{h}$ - Labels represent stream names from Figure 4.

19

Figure 7. Overlapping window of operating conditions (pressure and temperature) for reaction and distillation, for the DNPE system 

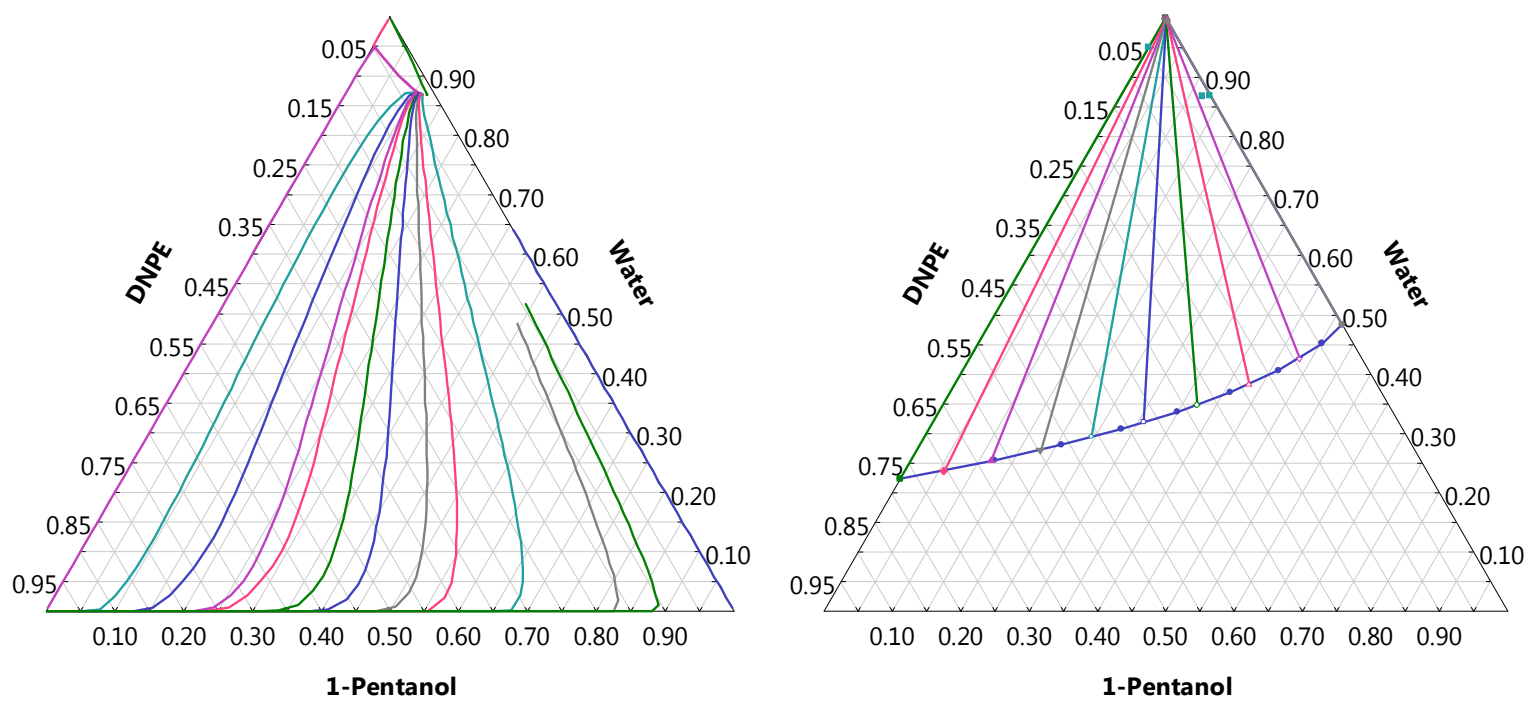

Figure 1. Residue curve map (RCM) and ternary diagram for the ternary mixture n-pentanol 4 water - DNPE (at $1.5 \mathrm{~atm}$ ), based on molar fractions of components

5

6

7

8

9

10

11

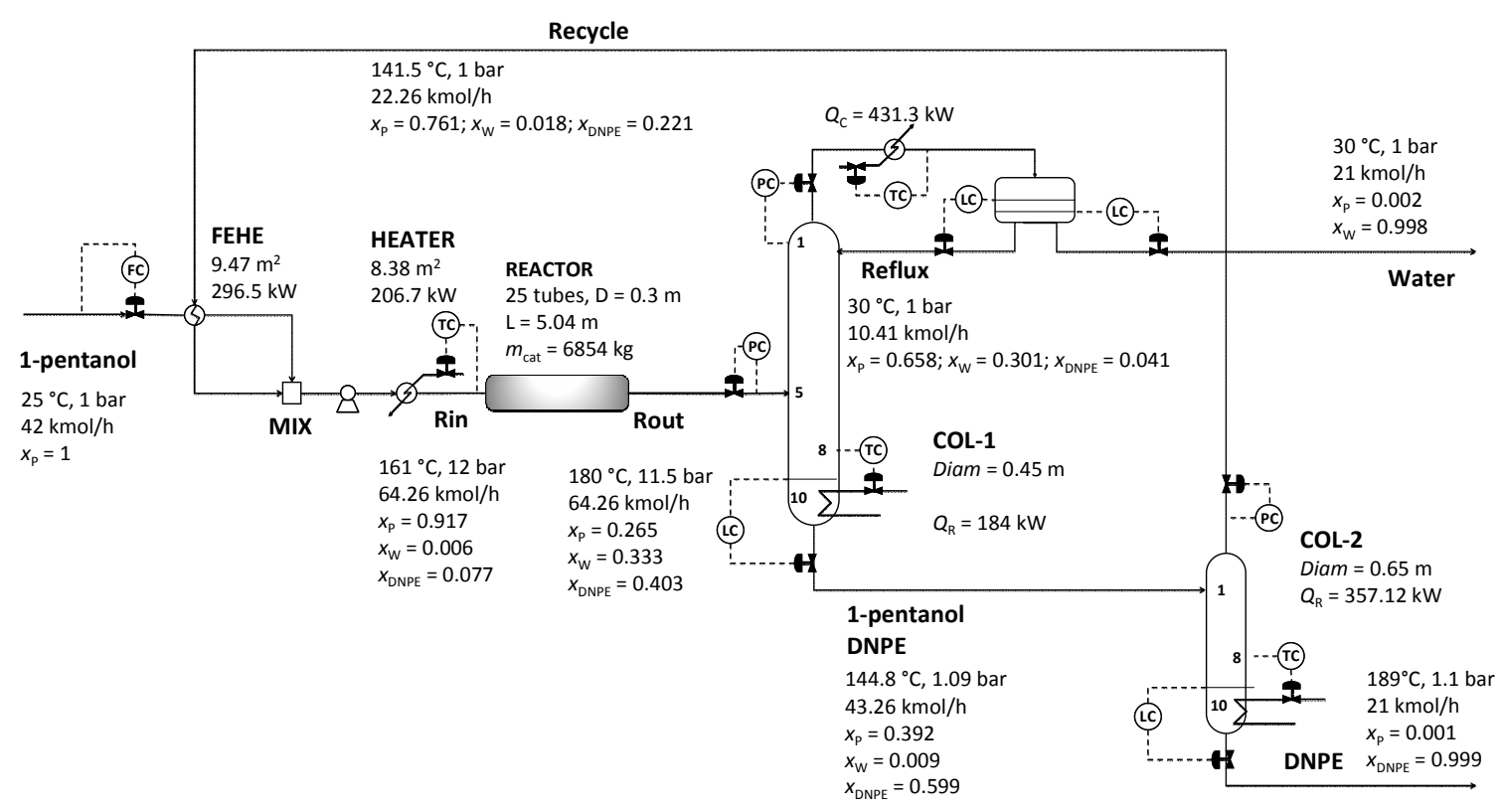

Figure 2. Flowsheet and plantwide control of a DNPE plant (reaction-separation-recycle) 

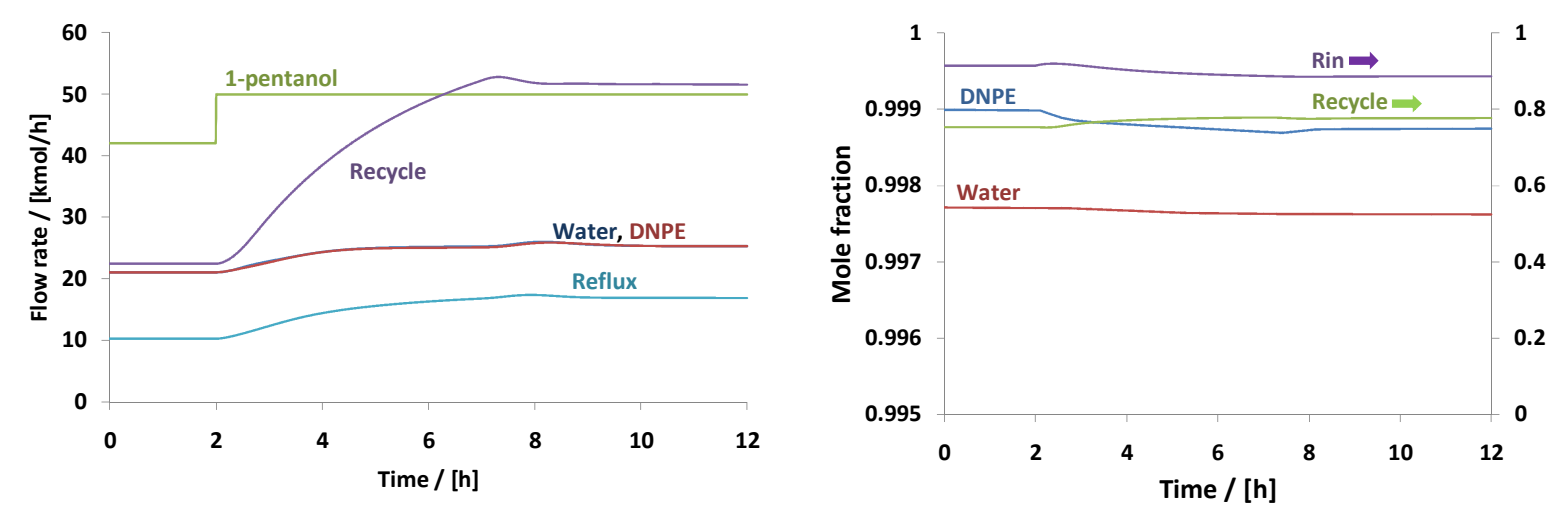

Figure 3. Results of the dynamic simulations for the DNPE production in a reactionseparation-recycle process (at time $\mathrm{t}=2 \mathrm{~h}$, the flow rate of fresh 1-pentanol is increased by $20 \%$, from $42 \mathrm{kmol} / \mathrm{h}$ to $50 \mathrm{kmol} / \mathrm{h}$ ) - Labels represent stream names from Figure 2. 

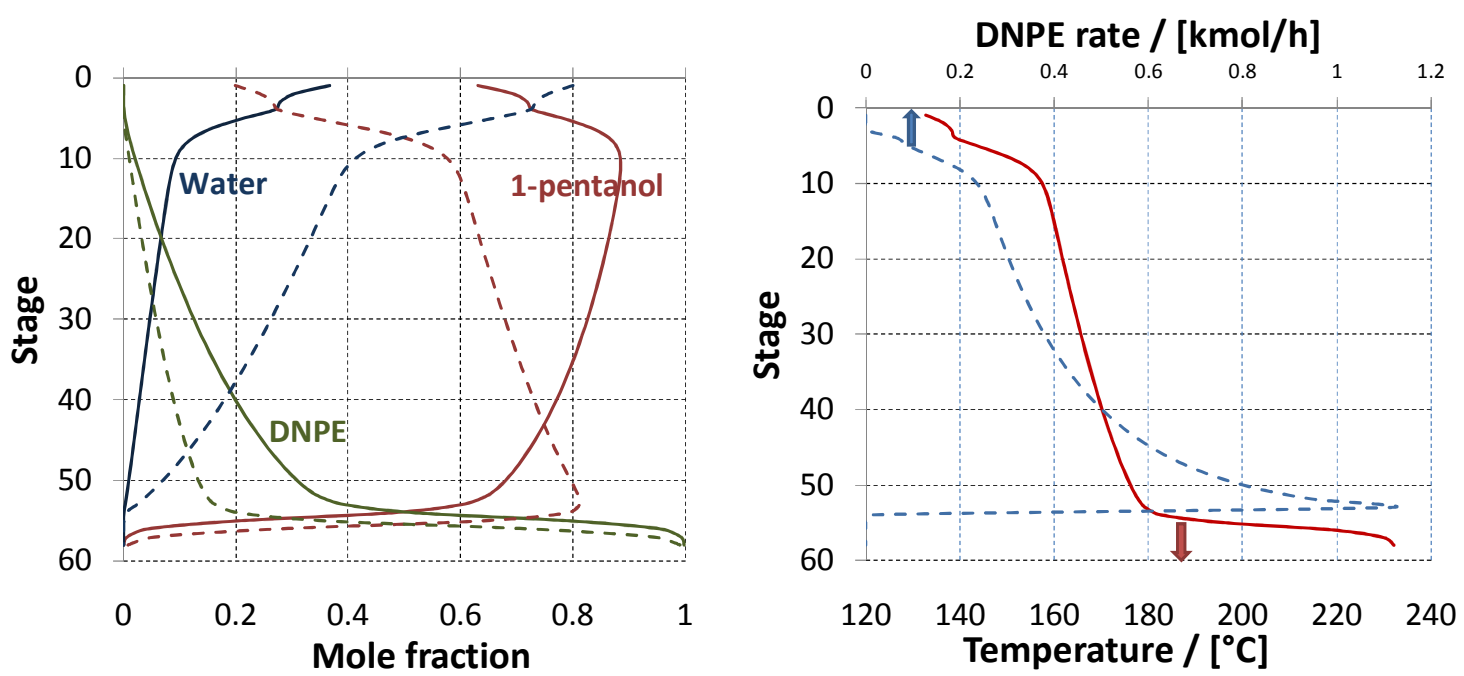

Figure 5. Profiles along the catalytic distillation column: molar composition (left), temperature and reaction rate (right)
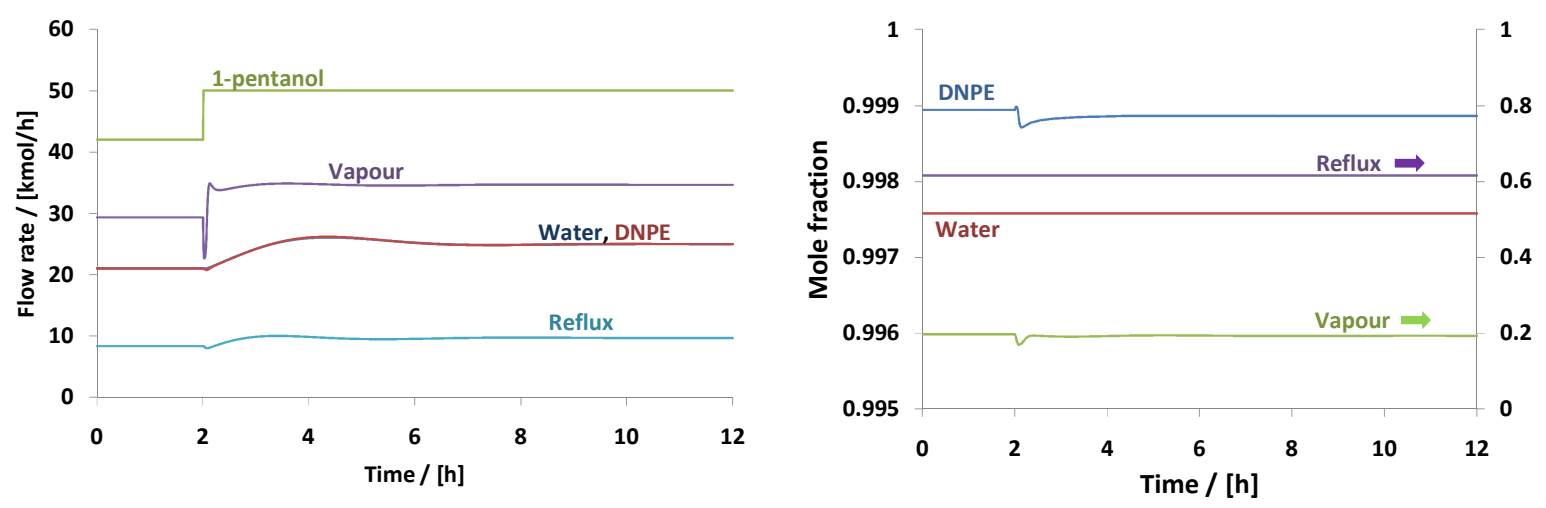

Figure 6. Results of the dynamic simulations for the DNPE production in a catalytic distillation column: at time $\mathrm{t}=2 \mathrm{~h}$, the flow rate of fresh 1-pentanol is increased by $20 \%$, from $42 \mathrm{kmol} / \mathrm{h}$ to $50 \mathrm{kmol} / \mathrm{h}$ - Labels represent stream names from Figure 4. 
1

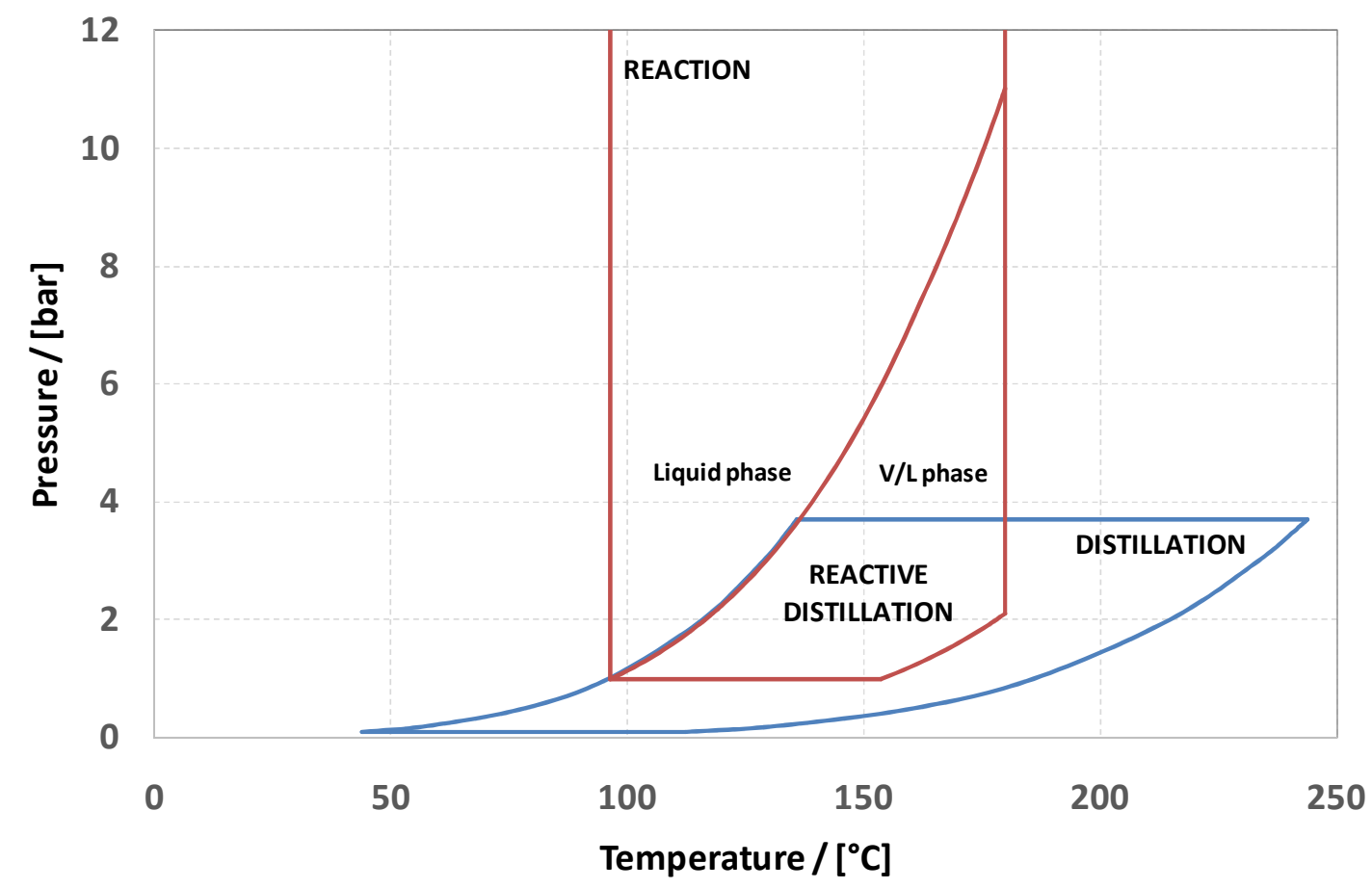

2

Figure 7. Overlapping window of operating conditions (pressure and temperature) for 4 reaction and distillation, for the DNPE system 